Hoylo thinks that soientists ought to turn instead to the "universal laboratory" of astronomy.

In the second lecture, Hoyle leads up to his concept of a "galactic culture" developed and promulgated by his envisaged exchange of information. Mankind has not yet become a subscriber, and Hoyle has some hints to offer as to how we should set about doing so.

In the last lecture, Hoyle discusses the distant future of man. He writes: "I am going to make one big hypothesis - a roligious hypothesis-that the emergence of intelligent life is not a meaningless accident. But I am not going to follow orthodox religions by presuming to know what that meaning is". He contemplates some of the implications of this hypothesis applied to the totality of life in the universe, and to the possibility of man being able to benefit from the experionce of life elsewhere in the universe. As Hoyle says, the realization of such a possibility would be "the most revolutionary step in human thinking".

W. H. MoCrEA

\section{SPACE MOSAIC}

Advances in Space Science and Technology

Vol. 6. Edited by Frederick I. Ordway, III. Pp. xvii +444. (New York: Academic Press, Inc.; London: Academic Press, Inc. (London), Ltd., 1964.) 107s. 6d.

DREVIOUS volumes of Advances in Space Science and Technology have been notable for providing excellent reviews of subjects not treated fully elsewhere in the literature. Sooner or later the supply of unhackneyed subjects will be exhausted; but that time has not yot como, and tho present volume again succoeds in charting little-trodden territory.

The first contribution, "Gravity", by B. S. DeWitt, may sound rather down-to-earth: but fortunately levity keeps breaking in, for Dr. DeWitt surveys the mysteries of gravity with witty aplomb and shows a healthy scepticism for currently accepted theories. It is quite an achievement to write at length about gravitation without involking mathomatical oquations, but Dr. DeWitt has succeeded. His article will be most useful to those who already know a little about Riemannian geometry, gravitational waves and the like. But less knowledgeable readers will also find much that is illuminating, for example, discussion of how far Einstein's theories are verified by observation. There is even a section on "the distant futuro", in which the author first disarms criticism by remarking that future advances will bo complotoly unexpected, and then meditates about the speculation that most of the energy in the universe may reside in wandering noutrinos wo can scarcely detect.

After these heady draughts, we are brought back to practical realitios with a discussion of staging in space launching vehicles, by G. K. C. Pardoe. The author first explains why staging is needed and then describes various existing multi-stage launching missiles: these are mostly United Statcs missiles, but tho European Launcher Development Organization launcher is also included. This useful and highly practical survey ends with a discus. sion of rocket mating probloms, that is, the ongineering difficulties of integrating rocket stages.

Saul Moskowitz and Paul Weinschel are the authors of tho third contribution, entitled "Navigational Instrumentation for Space Flight". They explain how to determino the position and course of a manned spacecraft, with the aid of obsorvations made on board tho oraft. The techniques used depend critically on the location of the navigator: in a near-Earth orbit, for example, it may be practicablo to utilizo the airglow, since the predominant atomic-oxygen line is observable as a groon glow contred at a height of about $100 \mathrm{~km}$; in Earth-Moon space the navigator can moasure tho directions of Earth, Moon and stars, and the diameters of Earth or Moon: in deep space the 'landmarks' are fewer, and his difficulties multiply. 'These various situations are thoroughly explorod.

The fourth chapter, by R. H. Waterman, jun., and L. G. Marts, deals with the commercial applications of space tochnology, the 'technological fall-out' as it is sometimes callod. The many people who scoff at this concept will be pleased to find the authors concluding that space activity has been more important in stimulating research genorally than in inspiring specific commercial applications. On the othor hand, tho scoffers will be dismayed to learn that the authors have identified 185 spoeific examples of 'tochnological transfer' in thirty different areas, which they describe in some dotail. This valuable review of a contentious subject provides a factual basis which has hitherto been lacking.

The last chapter, a survoy of missile launching facilities in the United States, is really a book in itself, sinco it runs to 192 pages. The authors, M. R. Sharpe, jun., and M. Lowther, have taken great pains to present all possible details of the American launching sites, with largo-scale maps, accounts of the tracking equipment available, photographs of launchings, etc. This appears to be the most comprehensive survey of its kind, with many details which have not been published before.

The book, besides boing well writton, is well printed and illustrated, and the air of uniformity about tho contributions suggests that a strong editorial hand has been at work.

D. G. KrNG-HeLE

\section{SPACE PHYSICS}

\section{Space Physics}

By Sir Harrie Massey. Pp. viii $+237+15$ plates. (Cam. bridge: At the University Press, 1964.) 35s. net.

HHIS compact book, based originally on the Scott Lectures delivered at the Cavendish Laboratory, Cambridge, in 1962, but since expanded rather considerably and brought up to date, gives an admirable introduction to all the main aspects of the use of space vehicles (sounding rockets, satellites and space probes) for scientific research. After a very broad, general survey of the field tho book begins with a good summary of what the reader needs to know about the technology of space vehicles. It then proceeds to describe their use in "inward-looking studies', mainly cloud meteorology and the determination of the geopotential.

A chapter follows which summarizes knowledge of the upper atmosphere as obtained from ground-level observations, and leads to a list of topics requiring investigation by means of space vehicles. The methods for so studying ono of these, the noutral atmospheric structure, aro then listed. Out of ten methods that are described, the paramount importance of that which is based on observing the perturbation of orbital elements due to atmospheric drag is well brought out, and the enormous volume of data obtained by this method is conveniently summarized.

The study of ionospheric structure by vehicles carrying probes is then set out. The fine structure under sporadic $\boldsymbol{E}$ conditions is well illustrated. The preliminary results of experimonts on board the U.K. satellite Ariel are illustrated in some detail, showing, for example, the important diurnal variations in electron tomperature.

The results of ultra-violet and X-ray observations of the Sun and stars from space vehicles are given, the solar spoctrum in these bands being discussed in somo detail. Tho value of ultra-violet measurements of stars of a wide range of types, to supplement knowledge of their atmospheres from observations in tho visiblo, is clearly brought out.

The evidence for the 'solar wind' is described, and detailed measurements of the variation of magnetic field in the rogion of interaction between the solar wind and the Earth's magnetosphere are discussed. The knowledgo 